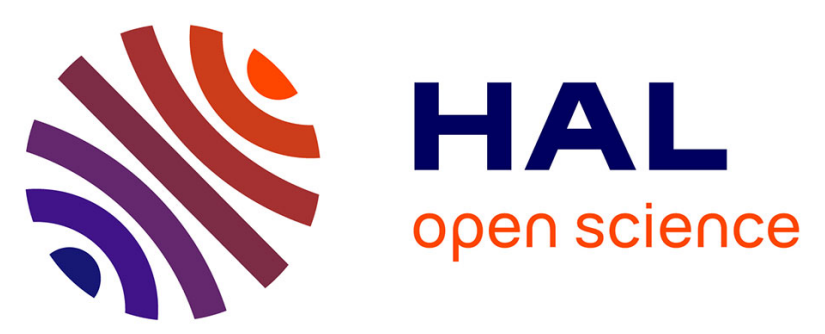

\title{
A correlation between tribological behavior and crystal structure of cobalt-based hardfacings
}

\author{
Elodie Cabrol, Christine Boher, Vanessa Vidal, Farhad Rezai-Aria, F.
} Touratier

\section{- To cite this version:}

Elodie Cabrol, Christine Boher, Vanessa Vidal, Farhad Rezai-Aria, F. Touratier. A correlation between tribological behavior and crystal structure of cobalt-based hardfacings. Wear, 2019, 426-427 (Part B), pp.996-1007. 10.1016/j.wear.2019.01.091 . hal-02100676

\section{HAL Id: hal-02100676 https://imt-mines-albi.hal.science/hal-02100676}

Submitted on 6 Nov 2019

HAL is a multi-disciplinary open access archive for the deposit and dissemination of scientific research documents, whether they are published or not. The documents may come from teaching and research institutions in France or abroad, or from public or private research centers.
L'archive ouverte pluridisciplinaire HAL, est destinée au dépôt et à la diffusion de documents scientifiques de niveau recherche, publiés ou non, émanant des établissements d'enseignement et de recherche français ou étrangers, des laboratoires publics ou privés. 


\title{
A correlation between tribological behavior and crystal structure of cobalt- based hardfacings
}

\author{
E. Cabrol ${ }^{\mathrm{a}, \mathrm{b}}$, C. Boher ${ }^{\mathrm{b}}$, V. Vidal ${ }^{\mathrm{b}}$, F. Rezaï-Aria ${ }^{\mathrm{b}}, \mathrm{F}$. Touratier $^{\mathrm{c}}$ \\ ${ }^{a}$ Université de Lyon, Ecole Nationale d'Ingénieurs de Saint-Etienne, LTDS, UMR CNRS 5513, France \\ ${ }^{\mathrm{b}}$ Institut Clément Ader (ICA), Université de Toulouse, CNRS, Mines Albi, UPS, INSA, ISAE-SUPAERO, France \\ ${ }^{c}$ Aubert \& Duval, France
}

\begin{abstract}
A B S T R A C T
This paper deals with the influence of the mechanisms of plasticity on the evolution of the friction coefficient in cobalt-based hardfacings. Particularly depending on the alloying element content and so on the stacking fault energy, plasticity in Co-based alloys may occur through mechanisms involving either perfect dislocations gliding and/or partial dislocation gliding. As the coalescence of stacking faults by partial dislocations promotes the phase transformation of the Co, this study focus on the impact of this phase transformation on the evolution of the friction coefficient.

Stellite 21 (Co-27Cr-5Mo-0.25C) hardfacings deposited on a steel substrate by two different processes, namely metal inert gas (MIG) and laser, are studied. The tribological properties are evaluated with a ring on disc tribometer under high load $(800 \mathrm{daN})$ and continuous sliding $(5 \mathrm{~mm} / \mathrm{s})$ at room and high temperatures $\left(450^{\circ} \mathrm{C}\right.$ and $600{ }^{\circ} \mathrm{C}$ ). The wear volume is characterized by confocal microscope. From micro-hardness measurements and SEM observations the work-hardening and the plastic strain of the Tribological Transformations of Surfaces are identified in relationship with chemical analysis (by EDS). Moreover X-rays diffraction and EBSD reveal the crystal structure evolution.

As-deposited Co-based hardfacings have a face-centered cubic (FCC) structure. Meanwhile depending on the process of deposition on the steel substrate, the nominal composition of the Stellite 21 can be modified due to dilution effect. So, the iron content is found to be higher in the MIG hardfacing than in the laser one, leading to different mechanisms of plasticity, respectively by perfect dislocations gliding and by phase transformation (FCC to hexagonal closed-packed (HCP)). Moreover, a significant influence of the phase transformation on the friction coefficient has been evidenced: without phase transformation the cobalt remains in the FCC structure and the friction coefficient is stable during the test, while a decrease of its value occurs during the FCC to HCP phase transformation.
\end{abstract}

\section{Keywords:}

Cobalt-based hardfacings

Plastic deformation mechanisms

Friction coefficient evolution

Phase transformation

Surface texturation

Work-hardening

\section{Introduction}

The industrial context of this study is the hot forging of aeronautic parts, which are mainly made of nickel-based alloys. During forging, the surfaces of the dies are exposed to a combination of thermomechanical loadings: preheating of the dies themselves (around $450{ }^{\circ} \mathrm{C}$ ), contact with the preheated forged metal $\left(>1000^{\circ} \mathrm{C}\right)$, mechanical pressure exerted by the press (several thousand tons) and friction induced at the interface between the die and the forged metal. In the case of hot forging of aeronautic parts, the main damage mechanism, limiting the lifetime of the dies to a few forged parts, is the large plastic deformation in the die radii. In this context, the steel dies are commonly hardfaced, on few millimeters thick, by a cobalt-based alloy (Stellite 21) manually deposited by arc welding process (MIG).
However, this "conventional" hardfacing is not satisfactory because it is itself strongly damaged after only a few forged parts. The aim of this study is to assess the surface damage mechanisms of cobalt-based hardfacings, especially induced by plastic deformation, in order to identify improvement ways to increase the service life of hardfaced forging dies.

The cobalt-based alloys, mainly known as Stellite ${ }^{\circledR}$, are cobalt alloys containing mainly $\mathrm{Cr}, \mathrm{C}, \mathrm{W}$ and/or Mo as alloying elements. The cobaltbased alloys are generally described as wear-resistant, corrosion-resistant and stable at elevated temperature. They are commonly used as hardfacing coatings of mechanical parts (forging dies, valve seats ...) in order to enhance their surface properties. Cobalt-based alloys can be deposited by processes using high energy density sources such as arc welding or laser cladding. 
The pure cobalt exhibits two allotropic phases: a high-temperature phase with a face-centered cubic (FCC) structure and a low temperature phase with a hexagonal closed-packed (HCP) structure. The allotropic transformation FCC-HCP of the cobalt is classified as martensitic as it takes place diffusionless, by shear mechanism. From a structural point of view, the FCC and HCP structures are closed-packed structures that only differs from the stacking order, respectively $A B C A B C . .$. and ABABAB.... The FCC-HCP martensitic transformation corresponds to a change in the stacking order by introduction of an intrinsic stacking fault, via the motion of single Shockley partial dislocations, each second compact planes (i.e. each second $\{111\}$ planes) [1]. The stability of the two allotropic phases is correlated to the stacking-fault energy (SFE) of the material that is the energy necessary to dissociate a perfect dislocation into two-partial Shockley dislocations. The SFE depends on the alloying elements: $\mathrm{Cr}$, Mo, W, Si stabilizes the HCP phase (i.e. increase the equilibrium temperature) and decrease the SFE, while Fe, Ni, Mn, V, $\mathrm{Ti}, \mathrm{C}$ stabilize the FCC structure (i.e. decrease the equilibrium temperature) and increase the SFE [2]. The equilibrium temperature for pure cobalt is about $419^{\circ} \mathrm{C}$ whereas, for example, it is about $970{ }^{\circ} \mathrm{C}$ for Co-27Cr-5Mo-0.05C alloy [3]. Despite this, the cobalt-based hardfacings can retain their FCC structure after deposition (and so because of high cooling rate), even at room temperature. This metastable FCC can be mechanically transformed into HCP structure by strain-induced transformation during tribological tests. The influence of the tribological test parameters (contact pressure [4], temperature [5]) and of the chemical composition of the Stellite [6,7] on this phase transformation has been investigated on various tribological devices. Person [4] has shown that there is a threshold of contact pressure (undefined, but between $20 \mathrm{MPa}$ and $2 \mathrm{GPa}$ ) above which the FCC to HCP phase transformation is observed. In addition, Atamert [6] and Kashani [7], have shown that the higher the iron content in the Stellite hardfacing, the lower the rate of FCC to HCP phase transformation during tribological tests.

The main objective of this study is to investigate the influence of the crystal structure (FCC or HCP) on the friction coefficient evolution in cobalt-based hardfacings. For that, a commercially available Stellite 21 hardfacing (Co-27Cr-5Mo-0,25C) deposited on a steel substrate has been studied. Two welding processes having a different heat input (MIG and LASER) have been chosen to study the influence of the deposition process on the wear behavior of the cobalt-based hardfacings. The "conventional" hardfacing (Stellite 21 deposited by MIG process) has thus been compared to the Stellite 21 deposited by laser process, an emerging process in the field of hot forging. The heat input difference has produced hardfacings with different microstructure sizes (solidification rate) and different iron contents (dilution effect). It will be shown that the iron content can play a key role as it influences the plasticity mechanisms involved during tribological loads by inducing or not FCC to HCP phase transformation. This differences have made it possible to highlight a clear correlation between the cobalt phase transformation and the evolution of the friction coefficient.

\section{Materials and experimental procedure}

\subsection{Materials}

The cobalt-based hardfacings investigated in this study are commercially available Stellites grade 21 alloys deposited onto 40NiCrMo18 tempered martensitic tool steel plates (Table 2) using the MIG and the laser processes. The schematic illustration of the MIG and the laser processes is shown in Fig. 1. For the MIG process, the filler material is on the form of a wire (Table 2) and the energy source is an electric arc. For the laser process, the filler material is on the form of powder (Table 2) and the energy source is a laser beam. The steel plates are pre-heated at $500{ }^{\circ} \mathrm{C}$ and a stress relieving has been applied after deposition $\left(2 \mathrm{~h} / 500^{\circ} \mathrm{C}\right)$. The main deposition conditions are listed in Table 1. After machining of the tribological samples, the thickness of
Table 1

Main conditions of deposition.

\begin{tabular}{lll}
\hline Deposition process & MIG & LASER \\
\hline Power (W) & 5200 & 4000 \\
Travel speed (mm/s) & 9 & 20 \\
Metal flow rate (g/s) & 1,56 & 0,58 \\
Welding energy (J/mm) & 578 & 200 \\
Number of layer & Mono-layer & Multi-layer \\
\hline
\end{tabular}

Table 2

Chemical composition of base material (40NiCrMo18) and filler materials (Stellite 21), as given by suppliers.

\begin{tabular}{lllllllll}
\hline & Co & Cr & Mo & Ni & Mn & Fe & Si & C \\
\hline $\begin{array}{l}\text { 40NiCrMo18 steel plate } \\
\quad \text { substrate }\end{array}$ & - & 1.5 & 0.5 & 4.5 & - & Bal. & - & 0.4 \\
$\begin{array}{l}\text { Stellite 21 wire filler } \\
\text { Stellite 21 powder filler }\end{array}$ & Bal. & 28.0 & 5.0 & 2.4 & 1.0 & 3.5 & 1.3 & 0.3 \\
& Bal. & 26.6 & 5.5 & 2.4 & 0.6 & 0.1 & 0.9 & 0.3 \\
\hline
\end{tabular}

the hardfacings is between 0.5 and $2 \mathrm{~mm}$ for the ST21-MIG hardfacings and around $4 \mathrm{~mm}$ for the ST21-laser ones. The thickness variations can be attributed to the technical difficulty due to the deposition processes and to the machining of the tribological samples from the hardfaced plates. The chemical composition of the hardfacings sliding layers are given in Table 3 . These results highlight, depending on the process, more or less important chemical composition modifications of the nominal chemical composition of Stellite 21 . The most impacted element is iron and it can be attributed to the dilution of the steel substrate in the hardfacing during the deposition process. The high iron content of $36.5 \mathrm{wt} \%$ for the ST21-MIG hardfacing can be correlated with the high welding heat input (i.e. welding energy) that is equal to $578 \mathrm{~J} / \mathrm{mm}$ and to the fact that it is a mono-layer hardfacing. For the ST21-laser hardfacings, the chemical composition of the external layer is sensibly the same as the nominal composition of the filler material, the iron content is less than $1 \mathrm{wt} \%$. This result can be explained by the fact that (i) the welding heat input is equal to $200 \mathrm{~J} / \mathrm{mm}$, so about three times lower than for the MIG process, and that (ii) the hardfacing is multilayer.

\subsection{Tribological device}

The tribological device is a high load and induction-heated tribometer where a level arm applies the defined normal load to a torus ( $R$ $=10 \mathrm{~mm}$ ) on plane contact configuration (Fig. 2). The tests are performed under dry conditions at room temperature (RT) and high temperatures $\left(450{ }^{\circ} \mathrm{C}\right.$ and $600{ }^{\circ} \mathrm{C}$ ). The upper specimens (Rings) were machined from cobalt-based hardfaced plates. The lower specimens (Discs) were machined from Inconel 718, a nickel-based superalloy (Al 0.5; C 0.04; Cr 18; Fe 18.5; Mo 3; Nb 5.2; Ti 0.9; bal. Ni) with a mean hardness of $466 \mathrm{HV}_{0.3}$. The target roughness was $\mathrm{Ra}=0.4 \mu \mathrm{m}$ for the rings and $\mathrm{Ra}=0.6 \mu \mathrm{m}$ for the discs. The tribological test parameters are summarized in Table 4: the static cobalt-based hardfacings slides against a rotation nickel-based superalloy counterface at a nominal velocity of $5 \mathrm{~mm} / \mathrm{s}$ and a nominal load of $8000 \mathrm{~N}$ for $4 \mathrm{~m}$. The friction coefficient is calculated from the recording of the normal and tangential forces (measured by deformation gauge sensors) by an acquisition system written in the Labview software, with an acquisition frequency of $10 \mathrm{~Hz}$. The friction coefficient is presented as a percentage of a constant value chosen arbitrarily for confidential reasons. The evolution of the friction coefficient is plotted versus the sliding distance and is treated by a moving average (160 points) to make trends easier to see. The room temperature experiments were repeated twice in order to ensure the reliability of the tribological device. 


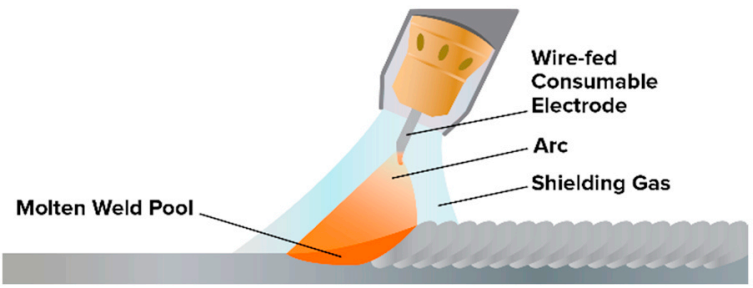

(a)

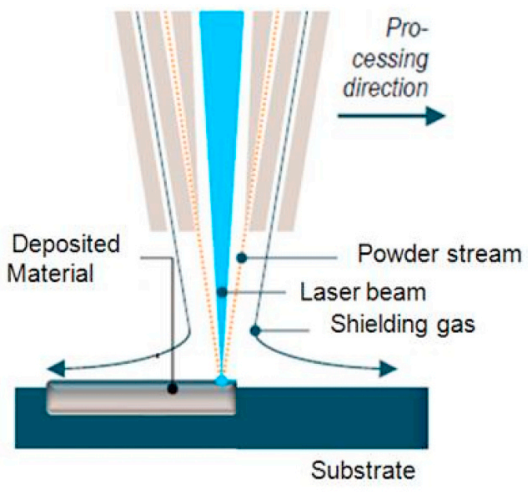

(b)

Fig. 1. Schematic illustration of the deposition processes: (a) MIG [8] and (b) LASER [9].

Table 3

Chemical composition of the hardfacings sliding surfaces (measured post mortem, in cross-sections, by EDS on areas of $120 \mu \mathrm{m} \times 25 \mu \mathrm{m}$; Carbon is not measurable by EDS).

\begin{tabular}{llllllll}
\hline & Co & Cr & Mo & Ni & Mn & Fe & Si \\
\hline ST21-MIG & Bal. & 19.0 & 2.9 & 3.0 & 1.2 & 36.5 & 0.9 \\
ST21-laser & Bal. & 26.6 & 4.6 & 2.5 & 0.8 & 0.5 & 0.9 \\
\hline
\end{tabular}

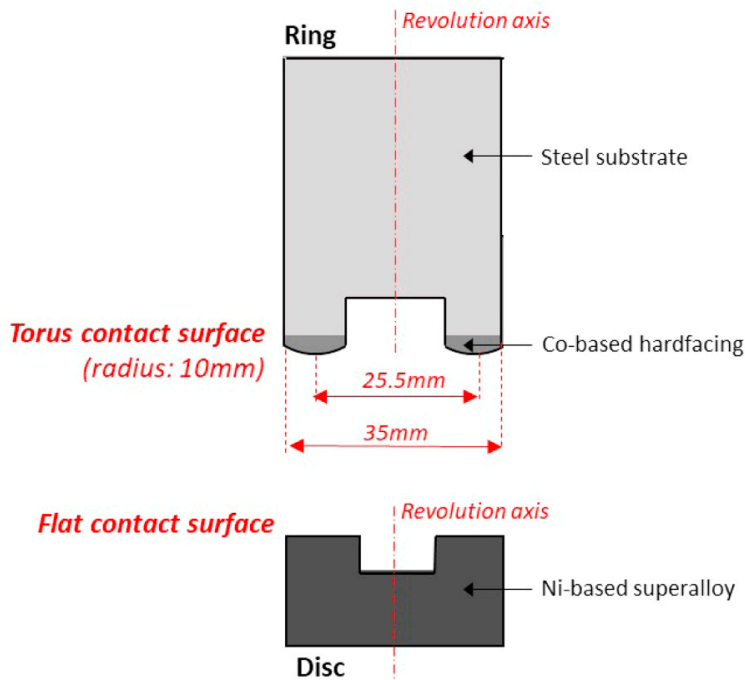

(a)

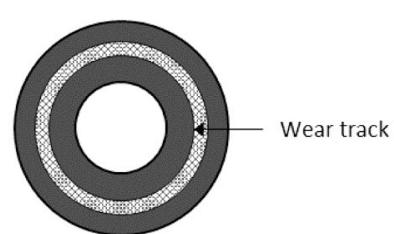

(b)

Fig. 2. Side view (a) and plan view (b) of the contact geometry between the ring (torus or horizontal cylinder shape) and the disc (plan shape).

\subsection{Characterizations}

\subsubsection{Wear investigations}

The wear volumes have been quantified by surface topography measurements using a confocal microscope (Altisurf $520^{\circ}$ from Altimet) with a chromatic confocal probe (measure range of $3 \mathrm{~mm}$ ) and an axial resolution of $90 \mathrm{~nm}$. Measurements have been performed before and after tribological tests in order to subtract the initial form of the sample linked to the radius of curvature. On each sample, four zones of $5 \mathrm{~mm}$ (step of $20 \mu \mathrm{m}$ ) $\times 11 \mathrm{~mm}$ (step of $5 \mu \mathrm{m}$ ) are scanned. The scanned surfaces are then treated with the software Altimap to extract the wear profile and the wear volume is finally calculated by multiplying the medium area of the wear profiles by the circumference of the wear track.

2.3.2. Microstructure investigations and chemical composition measurements

The microstructure characterizations have been performed by scanning electron microscopy (SEM) on a NOVANANOSEM ${ }^{\mathrm{TM}} 450$ from FEI. The samples have been cross sectioned parallel to the sliding direction, mounted in an electrically conducting material (KonductoMet ${ }^{\circ}$ ), grinded from 80 to 1200 grit paper, polished with diamond particles down to $1 \mu \mathrm{m}$. Finally, the microstructure has been revealed by an electrolytic etching with a $50 \mathrm{vol} \%$ hydrochloric acid and $50 \%$ vol ethanol reagent by using $0.8 \mathrm{~A}$ of current for $20 \mathrm{~s}$.

The chemical compositions have been measured in the upper layer (i.e. the sliding layer) of the samples by EDS. The analyses have been done in cross-sections, on an area of $120 \mu \mathrm{m} \times 25 \mu \mathrm{m}$, under an accelerating voltage of $15 \mathrm{kV}$.

\subsubsection{Hardness evaluations and mapping}

The hardfacings work-hardening has been measured by microhardness mapping (Vickers, $300 \mathrm{~g}$ ) on cross-section perpendicular to the sliding direction. Filiations have been performed in the plastically sheared area with an increment step of $100 \mu \mathrm{m}$ in depth every $250 \mu \mathrm{m}$ in width. The first measurement is located at $30 \mu \mathrm{m}$ from the surface because of the size of the Vickers indentations. The presented results are the average hardness profile of the cross-sections under the wear track.

Table 4

Tribological tests parameters.

\begin{tabular}{|c|c|c|c|c|c|c|}
\hline \multirow{2}{*}{$\begin{array}{l}\text { Normal load } \\
\text { N }\end{array}$} & \multirow{2}{*}{$\begin{array}{l}\text { Hertz contact pressure } \\
\text { MPa }\end{array}$} & \multicolumn{2}{|c|}{ Sliding speed } & \multicolumn{2}{|c|}{ Sliding distance } & \multirow{2}{*}{$\begin{array}{l}\text { Temperature } \\
{ }^{\circ} \mathrm{C}\end{array}$} \\
\hline & & $\mathrm{mm} / \mathrm{s}$ & Disc rotation rpm & $\mathbf{m}$ & Number of turns of the rotating disc & \\
\hline 8000 & 597 & 5 & 3.75 & 4 & 50 & RT, 450,600 \\
\hline
\end{tabular}




\subsubsection{Crystallographic structure investigations}

The crystallographic analyses (crystal structure and texture) have been achieved by X-ray diffraction (XRD) and electron backscatter diffraction (EBSD) techniques.

The XRD analyzes have been performed on top surface of the hardfacings to achieve a global measurement of the crystallographic phases and the grains orientations on an analyzed depth estimated to $10 \mu \mathrm{m}$. Classical $\theta-\theta$ measurements and pole figure measurements have been performed on a PANalytical X'Pert Pro diffractometer with a cobalt anticathode $(\lambda \mathrm{K} \alpha 1=1,789 \AA)$ using an iron filter to limit the fluorescence effect of the cobalt.

As a complement to XRD results, EBSD analyzes have been performed on cross-sections parallel to the sliding direction to focus on the gradients of both the FCC to HCP phase transformation and the preferred grain orientation on the 100 first micrometers under the sliding surface. The EBSD measurements have been performed on a SUPRA 55VP SEM from Zeiss and the data have been post-processed by different software from Oxford Instruments: Aztec ${ }^{\circ}$ for indexation, Mambo ${ }^{\circledR}$ for inverse pole figures and Tango for orientation maps. It can be noted that in order to minimize the induced residual deformation by mechanical preparation of the EBSD samples, a vibratory polishing has been performed on colloidal silica during $8 \mathrm{~h}$.

\section{Results}

\subsection{Characterization of the Co-hardfacings before tribological load}

\subsubsection{Microstructure investigations}

The microstructures of the two hardfacings are given in Fig. 3, as observed by SEM on a cross-section perpendicular to the substratehardfacing interface. Both hardfacings have shown morphologically textured columnar grains with dendritic microstructures. This morphological texture is characteristic of the welded hardfacings and results from the thermal gradient of solidification inherent to the welding processes [10]. The comparison of the MIG and laser hardfacings microstructures reveals different characteristic sizes of the primary dendrites widths, respectively $13 \mu \mathrm{m}$ and $6 \mu \mathrm{m}$. This difference can be correlated with the deposition rate: the higher the deposition rate, the thinner the microstructure (faster solidification rate). At a higher magnification, it is observed that the dendritic matrix is surrounded by interdendritic carbides (Fig. 4) which are essentially chromium-based (EDS analyses).

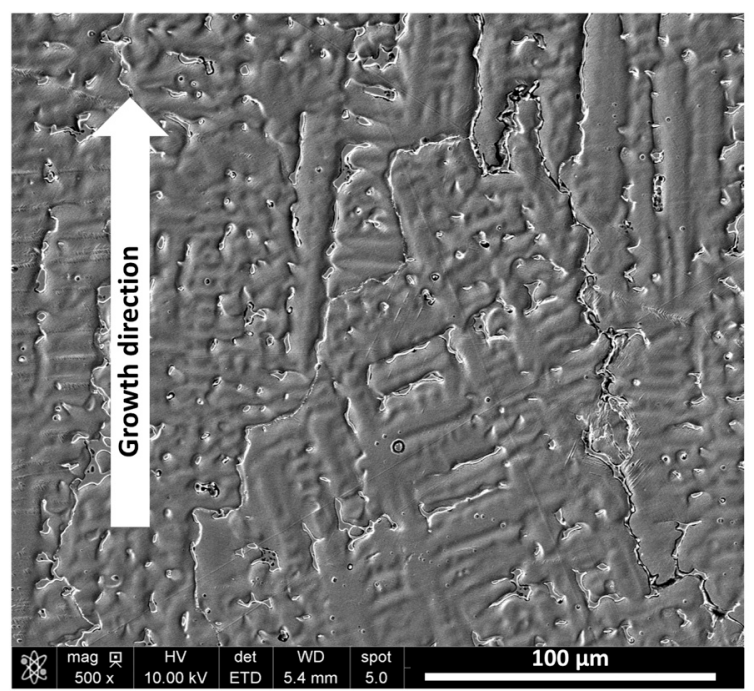

(a)

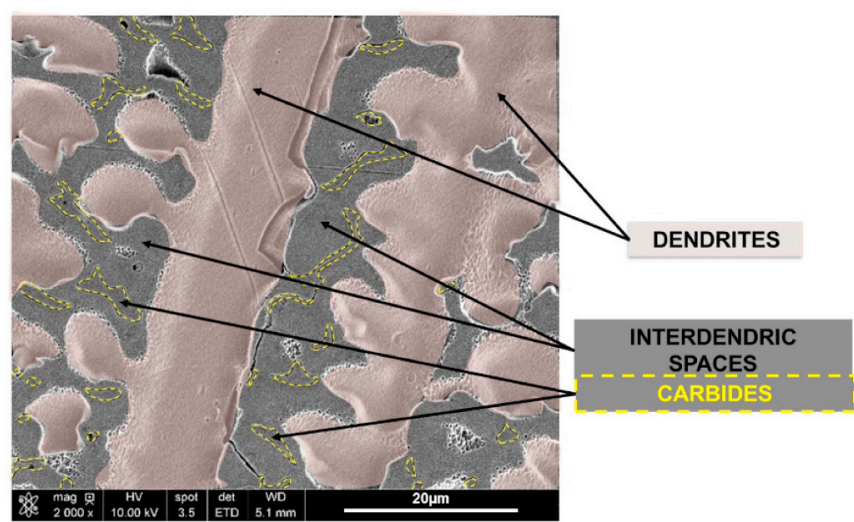

Fig. 4. Description of the characteristic microstructure of the Stellite 21 hardfacings as seen by SEM, example of the ST21-MIG hardfacing.

\subsubsection{Hardness evaluations}

The mean initial hardness is $307 \mathrm{HV}_{0.3}$ for the ST21-MIG hardfacings and $428 \mathrm{HV}_{0.3}$ for the ST21-laser hardfacings. The deposition process, as discussed in the previous paragraph, has induced different microstructures sizes that can affect the hardness due to the Hall-Petch effect. The ST21-laser hardfacings (thin microstructure) have a higher hardness than the ST21-MIG hardfacings (larger microstructure). The iron content (dilution effect) is also to be taken into account to explain this difference in initial hardness of the two hardfacings: the higher the iron content, the lower the content of carbide-forming elements $(\mathrm{Cr}$, Mo). These elements impact the structural hardness and the solid solution strengthening [11]. By decreasing their content (due to dilution), lower is the hardness.

\subsubsection{Crystallographic structure investigations}

According to classical $\theta-\theta$ XRD measurements, the as-deposited hardfacings have a FCC crystallographic structure, regardless of the deposition processing (Fig. 5). According to the Co-Cr binary equilibrium diagram for a chromium content between 20 and $30 \mathrm{wt} \%$, the RT stable phase of the cobalt has a HCP structure [12]. The presence of such "metastable" FCC phase has also been quoted by several authors $[4,13,14]$. It has been attributed to a non-equilibrium solidification due to the high cooling rate of the deposition processes [15]. The comparison of hardfacings XRD patterns with the FCC-Co JCPDS file which is for randomly oriented grains has shown significant differences in the

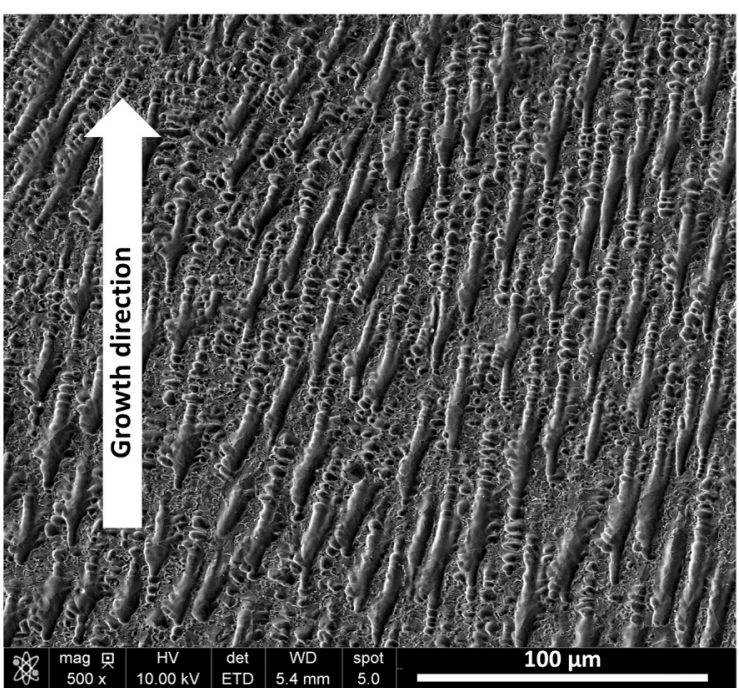

(b)

Fig. 3. Microstructures of the two investigated Stellite 21 hardfacings as seen by SEM: (a) ST21-MIG hardfacing, (b) ST21-laser hardfacing. 


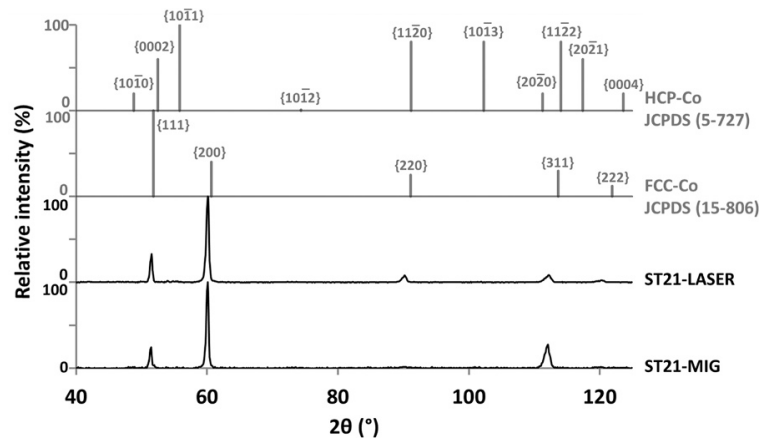

Fig. 5. XRD patterns of the ST21-MIG and ST21-laser hardfacings compared with JCPDS files of FCC-Co and HCP-Co.

relative intensities of the diffraction peaks. These differences highlight a preferred crystallographic orientation of the as-deposited hardfacings. As also been reported by other authors $[5,15]$, the $\{200\}$-FCC planes are preferentially oriented parallel to the sliding surface (i.e. perpendicular to the substrate-hardfacing interface). The growth direction of dendrites is generally $<100>$ in FCC structures. The grains oriented with the $<100>$ direction close to the heat flow extraction direction will grow fastest and hinder the growth of other grains, leading to the preferred crystallographic orientation.

The preferred orientations of the as-deposited hardfacings suggested by $\theta-\theta$ measurements have been confirmed by pole figure measurements (Fig. 6). For both hardfacings, the $\{200\}$-FCC pole figures (Fig. 6b, d) have shown a preferred orientation of the $\{200\}$-FCC planes almost parallels to the sliding surface. The normalized intensities of the poles have shown that the preferred orientation is more significant for the ST21-laser hardfacings $(\approx 14)$ than for the ST21-MIG ones $(\approx 11)$. Thus, the homogeneity of the melting pool is more or less important depending on the deposition process. This has been confirmed by the dispersion of the $\{200\}$-FCC planes which is particularly small for the ST21-laser hardfacings, indicating that the grains have the most pronounced preferred orientation. This can also be correlated to the solidification rate, the latter being faster for the laser process. Whatever the deposition process, a slight inclination of about $10^{\circ}$ of the $\{200\}$-FCC planes with respect to the sliding surface can be noted. These inclination can be explained by the inclination of the torch and so of the heat flux direction, but also by the solidification isotherms in the melting pool generated by the advancement of the torch head that promote the preferred grain growth "parallel" to the welding direction. This type of inclination has also been observed by Chassignole in the context of austenitic stainless steel welds of piping systems [16]. The $\{111\}$-FCC pole figures (Fig. 6a, c) have shown no preferred orientation indicating a randomly distribution of the grains in the lateral direction.

\subsection{Characterization of the Co-hardfacings after tribological load}

\subsubsection{Friction coefficient}

3.2.1.1. Evolution of the friction coefficient. The evolution of the friction coefficient versus the sliding distance (Fig. 7) exhibits behaviors extremely different from the surfaces of the two studied hardfacings, MIG and LASER, in response to a tribological loading. Thus, the evolution of the friction coefficient versus sliding distance makes it

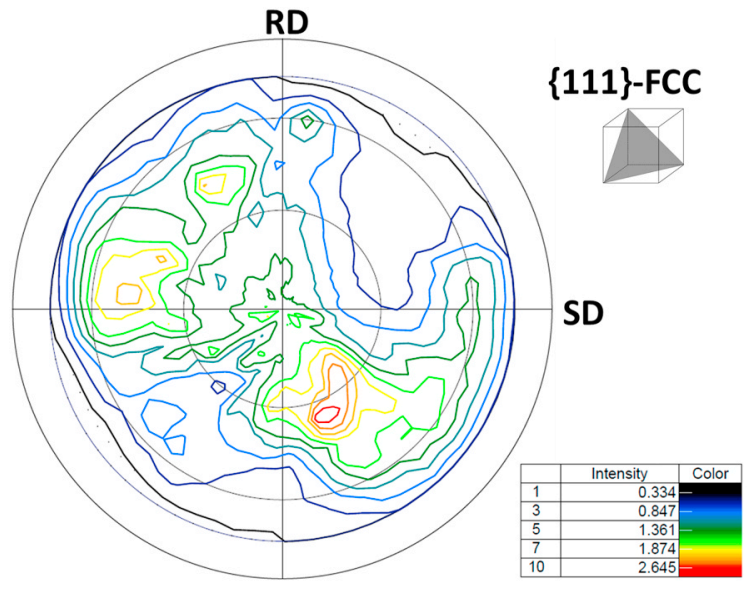

(a)

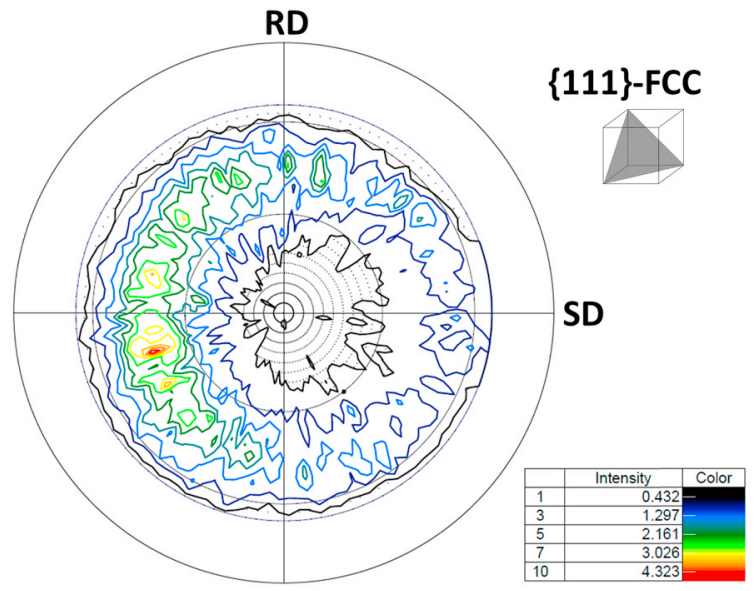

(c)

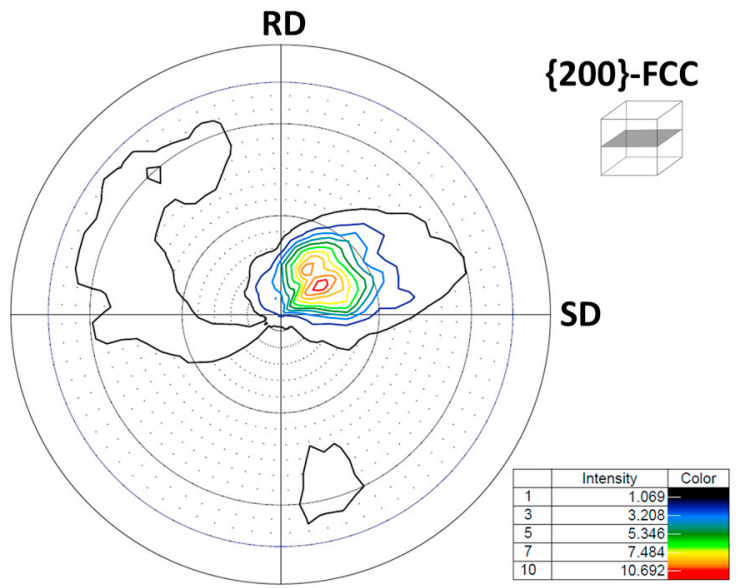

(b)

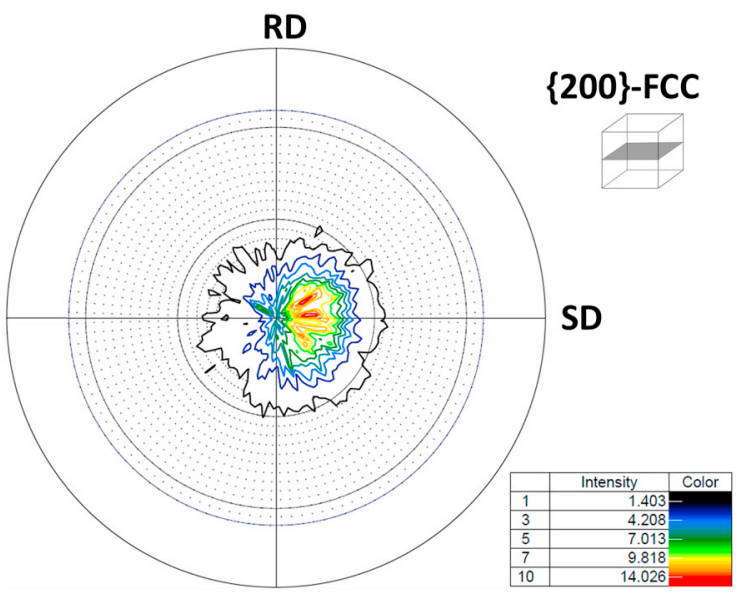

(d)

Fig. 6. $\{111\}$-FCC and $\{200\}$-FCC pole figures of (a, b) ST21-MIG hardfacings and (c, d) ST21-laser hardfacings; SD: sliding direction, RD: radial direction. 


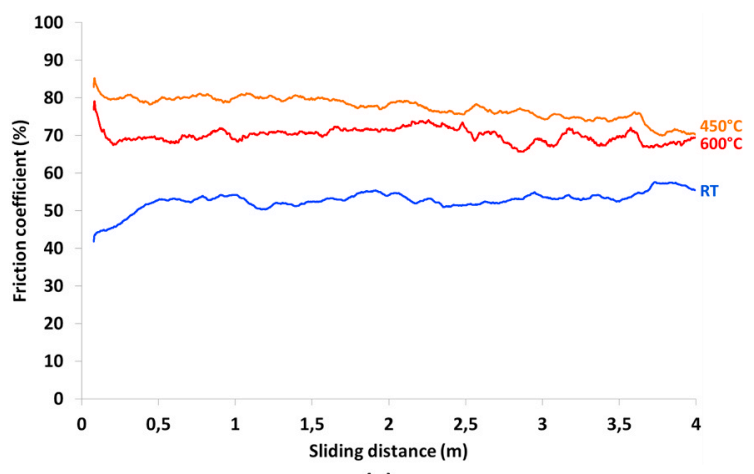

(a)

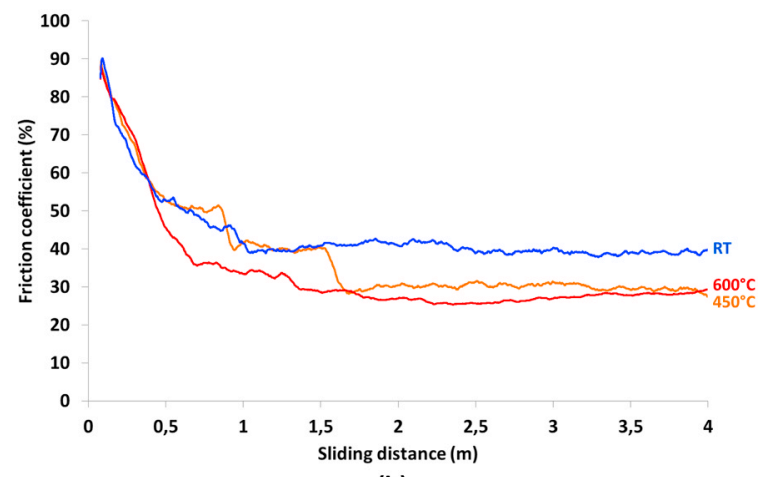

(b)

Fig. 7. Friction coefficient versus sliding distance of (a) ST21-MIG hardfacings and (b) ST21-laser hardfacings.

possible to identify two types of behavior:

- A stable friction coefficient during all the friction tests: the ST21MIG hardfacings, whatever the test temperature, exhibit a friction coefficient rapidly stabilized with respect to the sliding distance.

- An evolution of the friction coefficient during the friction tests: A first period with continuously decreasing friction coefficient followed by a constant friction coefficient for the remainder of the sliding distance: the ST21-laser hardfacings, whatever the test temperature, exhibit an immediate and progressive drop in the friction coefficient followed by a steady-state value. The steady-state value has been reached for sliding distances lower than $2 \mathrm{~m}$.

3.2.1.2. Value of the steady-state friction coefficient. The value of the steady state friction coefficient is depending on both the hardfacings process and the test temperature, with some differences between these two parameters (Fig. 8).

For the ST21-MIG hardfacings, high temperature friction coefficients are higher than RT one. This behavior is quite different for the ST21-laser hardfacings, where high temperature friction coefficients are lower than RT one. No significant differences can be underlined for the effect between the two high temperatures of $450^{\circ} \mathrm{C}$ and $600{ }^{\circ} \mathrm{C}$.

\subsubsection{Wear volume}

The wear volume of the hardfacings is presented versus deposition process and versus temperature in Fig. 9. The ST21-MIG hardfacings exhibit a higher wear volume than the ST21-laser hardfacings. This wear volume evolution could be related to the initial microstructure fineness and hardness: the thinner and harder the microstructure, the lower the wear volume.

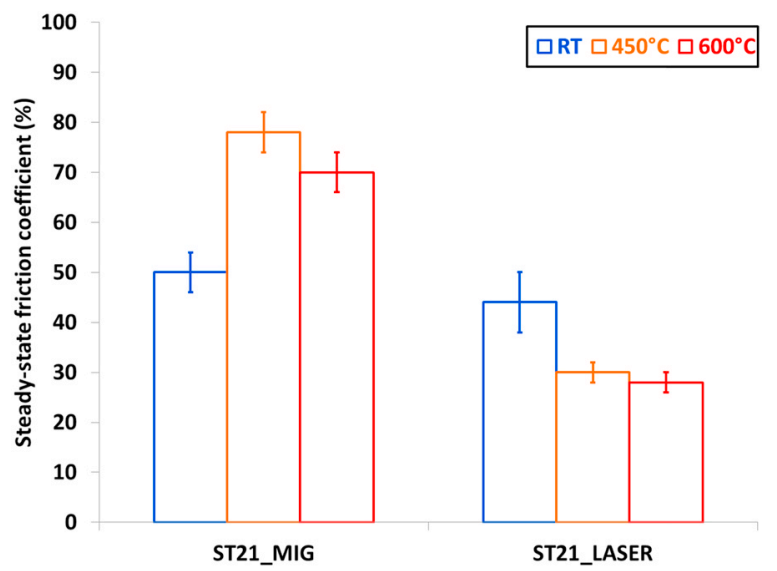

Fig. 8. Steady-state friction coefficient of the ST21-MIG and the ST21-laser hardfacings at different test temperature.
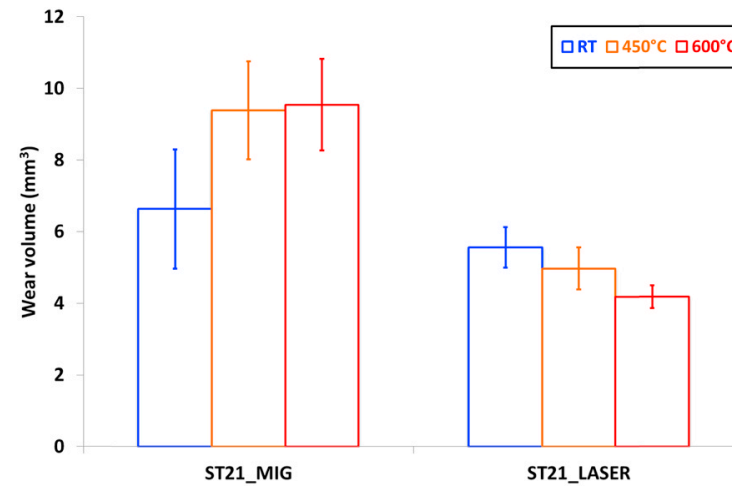

Fig. 9. Wear volume of the hardfacings.

It can also be observed that the wear volume tends to increase with the temperature for the ST21-MIG hardfacings and to decrease with the temperature for the LASER-hardfacings. The evolutions of wear volumes are close from the evolutions of the steady friction coefficients. As previously, these values are depending on both hardfacing deposition conditions and on test temperatures with small differences between the high temperature tests.

\subsubsection{Cross-section observations}

After tribological tests, microstructural observations have been carried out by SEM, in cross-sections of the rings, in the direction parallel to the sliding. The plastic deformation of the Stellite is well demonstrated, with a reorientation of the dendrites according to the sliding direction (Fig. 10, Fig. 11). Whatever the hardfacing, at the extreme surface of the wear track, the dendrites are sheared and plastic deformation is observed for all test parameters.

The plastic deformation of dendrites is more important for ST21MIG than for ST21-LASER. For ST21-MIG hardfacings, the dendrites are completely "rolled" in extreme surface, their principal axes are no longer perpendicular, but are parallel to the sliding surface and the width of the dendrites becomes submicronic. The deformation has been estimated at several hundreds of percent. Regarding the affected depth, the micrographic observations show a plastic strain evolution of the dendritic matrix over less than one hundred first micrometers.

At higher magnification, it can be observed that the plastic deformation is totally supported by the dendritic matrix and that the interdendritic carbides are totally or partially sheared. The carbides and/ or debris of carbides are thus more or less "embedded" in the plastic flow and become markers of the plastic deformation by shearing. On the firsts micrometers under the contact surface the microstructure of the hardfacing is almost no longer recognizable.

From these observations, it can be concluded that one of the mechanism of accommodation of the velocity differences in the contact 


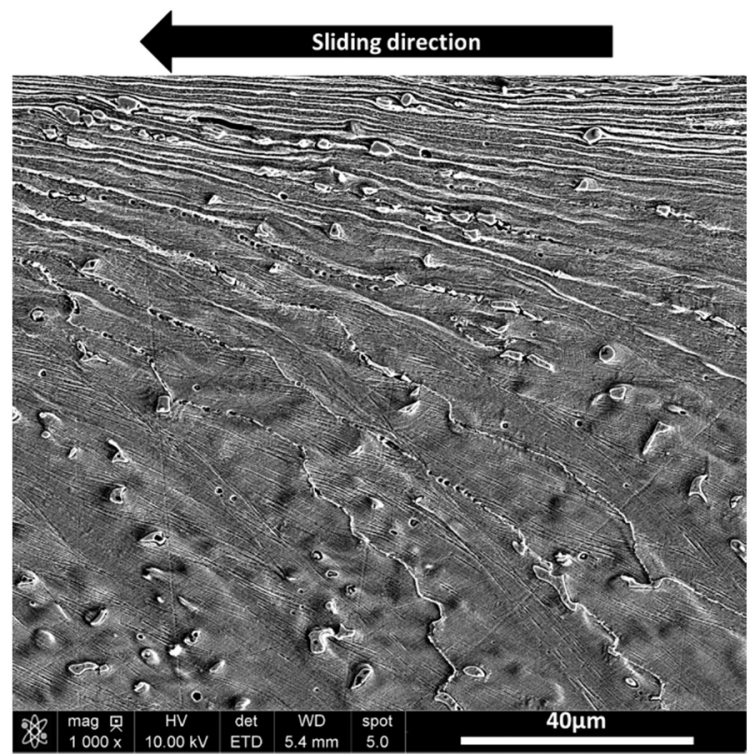

(a)

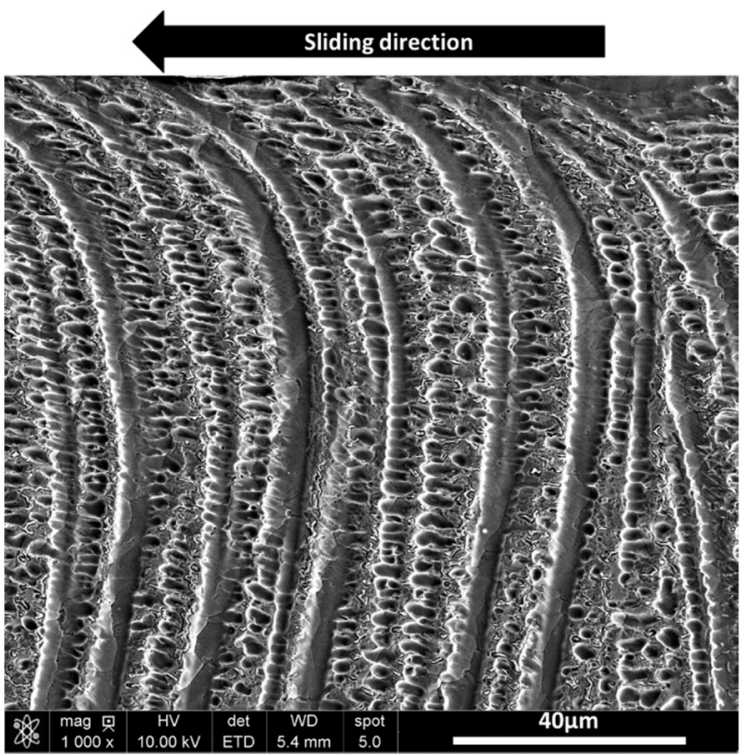

(b)

Fig. 10. Plastic deformation of the upper part of the rings observed in cross-section by SEM for (a) ST21-MIG hardfacing and (b) ST21-laser hardfacing; Examples of the tests performed at $4500^{\circ} \mathrm{C}$.

between the static ring and the rotating disc is the plastic deformation of the dendrites and the interdendritic spaces under the shearing effect.

\subsubsection{Hardness evolution and affected depth}

The work-hardening has been determined by harness mappings (Vickers, $300 \mathrm{~g}$ ). The measurements verify that, whatever the hardfacing deposition process, the Stellites are work-hardened under tribological load, through the width of the wear track. Moreover, according to the average hardness profiles under the wear track (Fig. 12), a gradient of hardness is observed on the first $500 \mu \mathrm{m}$ from the sliding surfaces, independently of the test parameters (Fig. 12).

In the upper part of the TTS, the hardness reached maximum values of about $600 \mathrm{HV}_{0.3}$ for the ST21-MIG hardfacings and about $700 \mathrm{HV}_{0.3}$ for the ST21-laser hardfacings. These values seem to correspond to the "ultimate" hardness of the hardfacings before emission of wear particles in the contact. For both hardfacings, a strain-hardening is observed and the affected depth from the sliding surface is about $500 \mu \mathrm{m}$. The difference of "ultimate" hardness can be attributed to several elements: the microstructure size of the hardfacings, the iron content on the hardfacing and/or the plasticity mechanisms involved during tribological test.

Contrary to the SEM observations, presented earlier, the hardness measurements reflect more accurately the thickness actually affected in the regions beneath the sliding surface (Fig. 13).

\subsubsection{Phase analyses and preferred orientation}

3.2.5.1. Phase analyses. The variations of tribological characteristics, such as friction coefficient evolution, wear rates, work-hardening variations and also cross-section observations have conducted to be interested more precisely on the modification of the phases of the

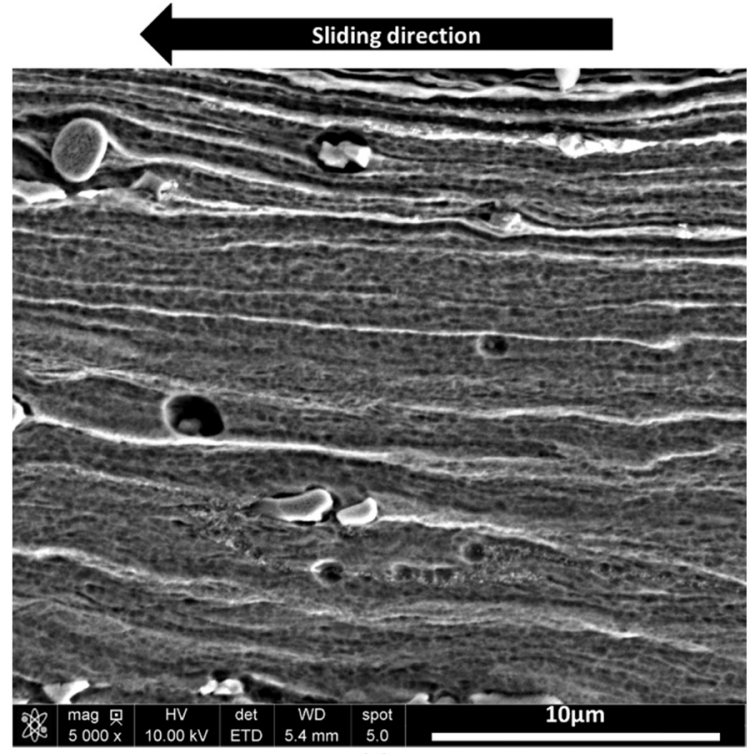

(a)

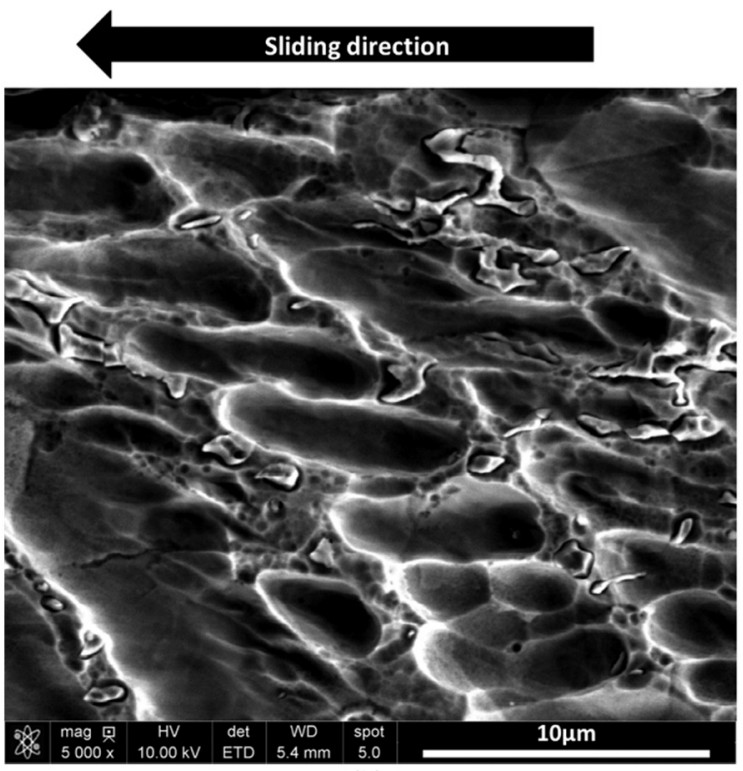

(b)

Fig. 11. Plastic deformation of the upper part of the rings observed in cross-section by SEM for (a) ST21-MIG hardfacing and (b) ST21-laser hardfacing; Examples of the tests performed at $450^{\circ} \mathrm{C}$. 


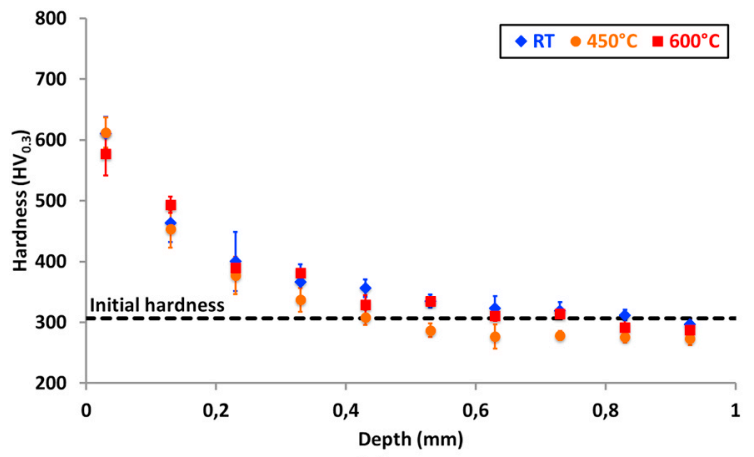

(a)

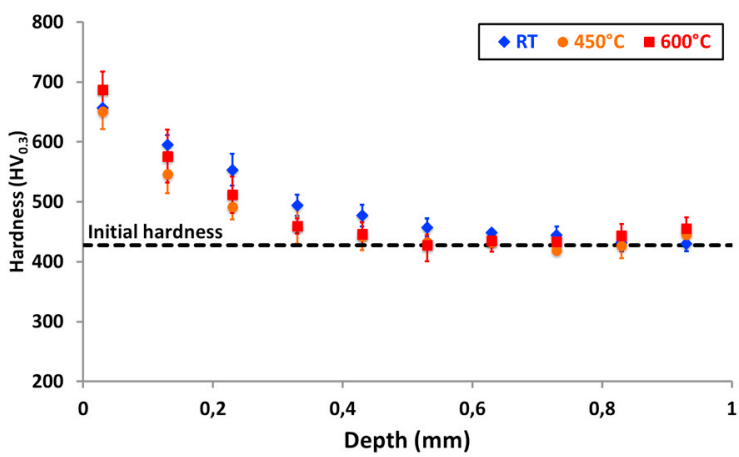

(b)

Fig. 12. Evolution of the hardness of the hardfacings under tribological loads for (a) ST21-MIG hardfacing and (b) ST21-laser hardfacings.

surfaces of the hardfacings under tribological loadings.

As it was mentioned, the initial structure of the hardfacings is "metastable" FCC type. This structure is due to the fast solidification rate inherent to the deposition process. The XRD analyses realized in top surface, in the wear track of the samples, have shown different phases after tribological tests, depending on the deposition process (Fig. 14). In the Stellite 21 deposited by MIG process (Fig. 14a), for all test temperatures, only the FCC-Co phase has been observed. In the Stellite 21 deposited by laser process (Fig. 14b), for all test temperatures, only the HCP-Co phase has been observed. For ST21-laser hardfacings, the FCC to HCP phase transformation has therefore been produced under tribological loadings regardless of the test temperature.

\subsubsection{Grain orientation}

3.2.5.2.1. XRD analyses in $\theta / \theta$ configuration. The study of relative intensities of diffraction peaks has given information on the preferential orientation of the grains after tribological loads.

Concerning the hardfacings retaining a FCC structure after tribological test (i.e. ST21-MIG), the relative intensities of the five firsts diffraction peaks have been calculated and compared with the JCPDSFCC-Co (Fig. 15). The significant increase in the relative intensities of some diffraction peaks compared to the JCPDS-FCC-Co has revealed preferred orientation of the grains (Fig. 15). These results confirm that before tribological test, the hardfacings have an initial preferred orientation with the $\{200\}$-FCC planes predominantly parallel to the sliding surface (as already revealed by pole figure measurement). These results have also shown significant modifications about the grain orientation after tribological tests. Indeed, most of the grains are oriented with their $\{111\}$-FCC planes parallel to the sliding surfaces. Note that these latter belongs to the main slip planes (i.e. the highest atomic density planes) in a FCC structure. The grains orientations evolution under tribological loadings corresponds to the self-accommodation of the FCC slip planes (i.e. $\{111\}$-FCC planes) along the sliding surface and can be directly linked to dislocation activity.

Concerning the hardfacings transformed from FCC to HCP phase during tribological test (i.e. ST21-LASER), the relative intensities of the five firsts diffraction peaks have been calculated and compared with the JCPDS-HCP-Co (Fig. 16). The differences of relative intensities peaks have highlighted that the HCP phase induced during tribological tests has a preferred crystallographic orientation. Indeed, the majority of the crystallographic planes that are parallel to the sliding surfaces are \{0002\}-HCP.

These classic XRD measurements have shown significant evolutions of the preferred orientation of the grains under friction loading. Whatever the phase present at the extreme surface after tribological test, FCC or HCP, the highest atomic density planes are parallel to the sliding surface, respectively $\{111\}$-FCC and $\{0002\}$-HCP.

3.2.5.2.2. EBSD analyses. EBSD investigations have been carried out on ST21-LASER hardfacings after tribological test only at RT. The analyzed area is situated on the firsts $90 \mu \mathrm{m}$ under the sliding surface (Fig. 17).

3.2.5.2.3. Band contrast map. The band contrast map is

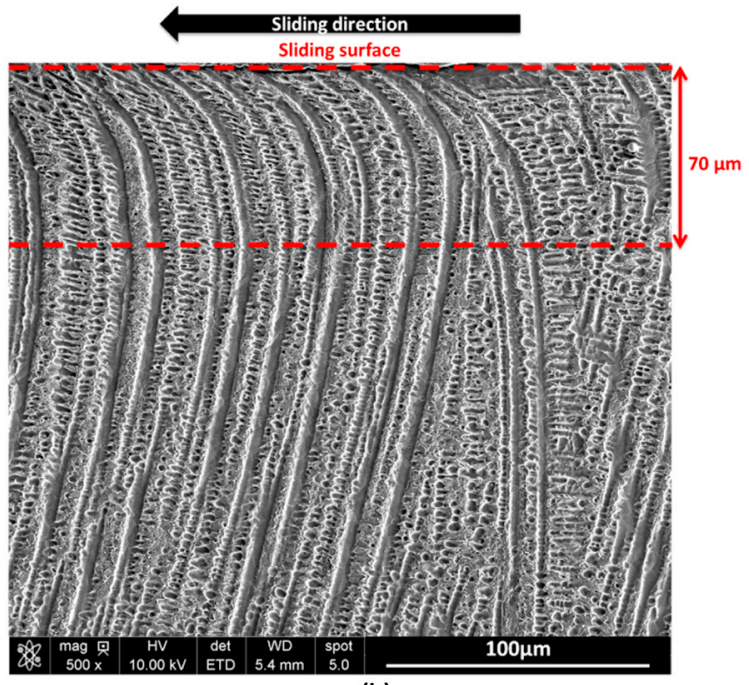

(b)

Fig. 13. Comparison of the affected depth by plastic deformation between (a) hardness measurements and (b) SEM observations (example of the Stellite 21 deposited by laser process with the test at $450{ }^{\circ} \mathrm{C}$ ). 


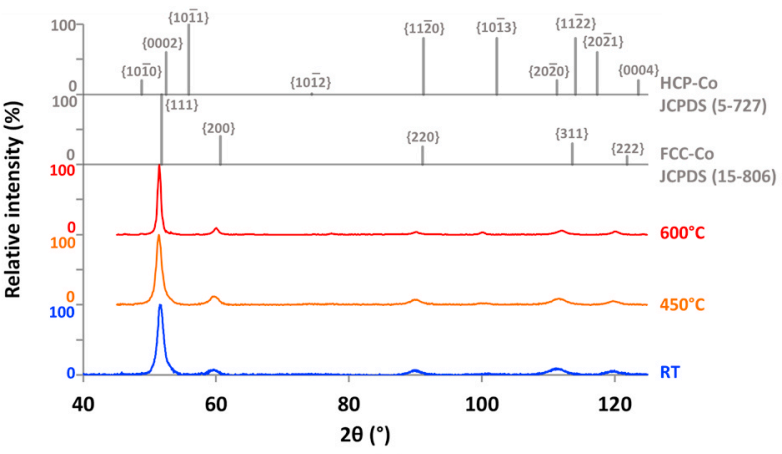

(a)

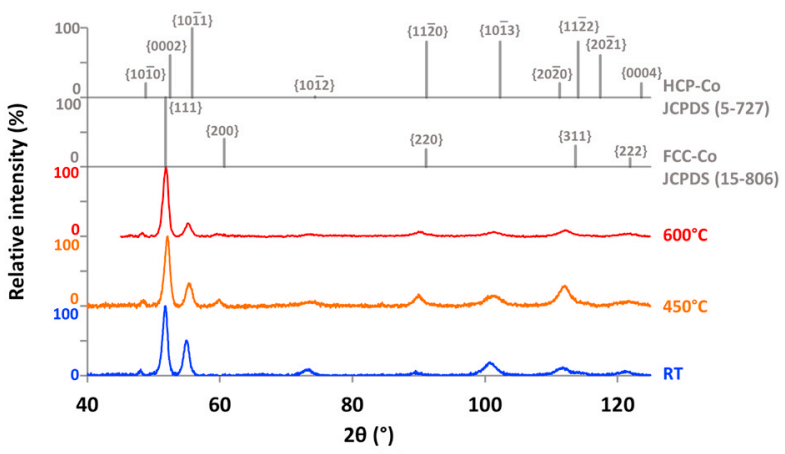

(b)

Fig. 14. XRD patterns of worn surfaces compared to JCPDS files of FCC-Co and HCP-Co for (a) ST21-MIG hardfacings and (b) ST21-laser hardfacings.

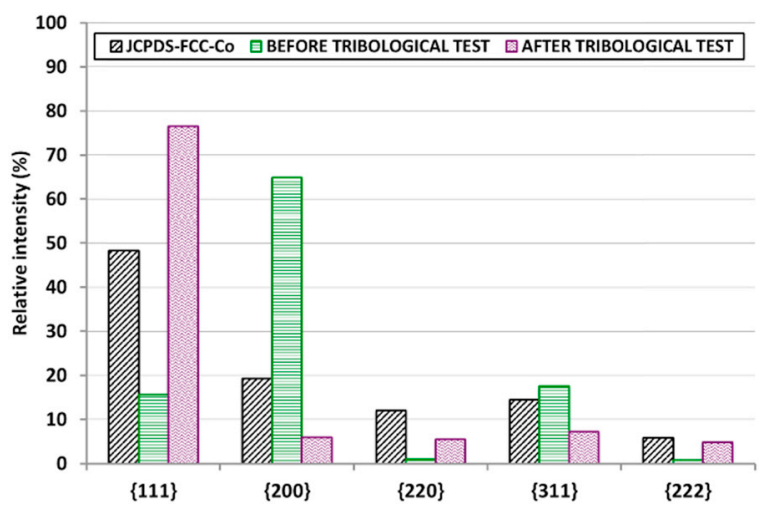

Fig. 15. Comparison of the relative intensity of the diffraction peaks between the JCPDS file of FCC-Co, the ST21-MIG hardfacing before tribological test and the ST21-MIG hardfacing after tribological test. (Example of RT tribological test).

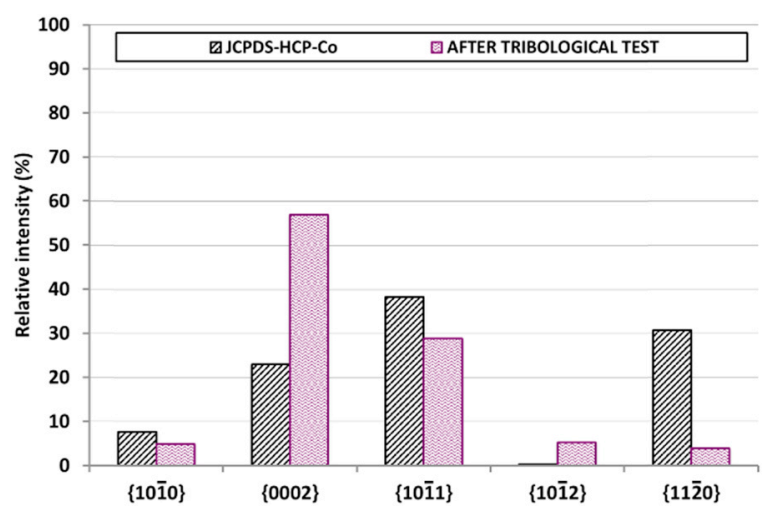

Fig. 16. Comparison of the relative intensity of the diffraction peaks between the JCPDS file of FCC-Co, the ST21-LASER hardfacing before tribological test and the ST21-LASER hardfacing after tribological test. (Example of RT test).

representative of the presence of defects (such as dislocations, stacking defects, grain boundaries, etc.) in the material (the more defects there are, the darker the color). After tribological test, the band contrast map (Fig. 18-a) has revealed a large number of defects that cause significant difficulties for extreme surface analysis despite careful sample preparation. These defects can be related to the intrinsic workhardening of the material. They induce indexation difficulties on the first $10-20 \mu \mathrm{m}$ under the sliding surface (Fig. 18-a). The evolution of the indexing rate versus depth (Fig. 18-b) has confirmed the presence of defects in the extreme surface of the hardfacing (less than $10 \%$ of indexation in the first $20 \mu \mathrm{m}$ ). The indexation rate is increasing with the depth and $100 \%$ indexation is obtained at about $90 \mu \mathrm{m}$ from the sliding

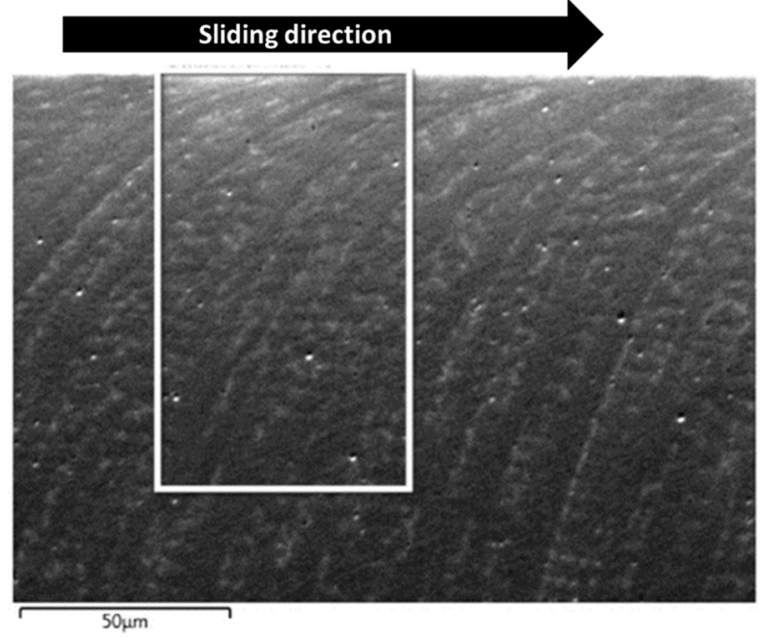

Fig. 17. SEM image of the analyzed area by EBSD.

surface. This observation can be considered as the signature of a gradient of defects on the tribological surfaces of the hardfacings.

3.2.5.2.4. Phase contrast map. The phase contrast map (Fig. 19) has revealed the presence of the FCC and HCP phases and has shown their distribution in the Tribologically Transformed Surface (TTS) of the sample. An FCC to HCP phase transformation evolution is observed in the TTS. The HCP-Co phase content as a function of depth (Fig. 20) has shown that the FCC to HCP strain-induced phase transformation is almost totally achieved (>90\%) on the first $20 \mu \mathrm{m}$. Although the indexation rate is extremely low in this analyses area (Fig. 18), based on the results of conventional XRD (which analyzed a depth of about $10 \mu \mathrm{m}$ ), it can be considered that the HCP-Co content is representative of reality. The HCP-Co phase content decreases between $20 \mu \mathrm{m}$ and $70 \mu \mathrm{m}$ and the initial FCC-Co structure is found at a depth of about $70 \mu \mathrm{m}$.

3.2.5.2.5. Crystallographic orientation maps. For these maps, the chosen axes are the same as the SEM image axes (Fig. 17). The $\mathrm{X}$ axis corresponds to the horizontal axis of the image (sliding direction), the $\mathrm{Y}$ axis corresponds to the vertical axis of the image (normal to the friction surface) and the $\mathrm{Z}$ axis corresponds to the normal axis to the image (normal to the direction of slip).

The orientation of the FCC-Co and the HCP-Co are represented using Inverse Pole Figures which shows the distribution of crystallographic directions parallel to certain sample directions. For the FCC-Co, the IPF $\mathrm{Y}$ is presented on Fig. 21 and for the HCP-Co, the IPF X, Y and Z are presented on Fig. 22.

For the retained FCC phase, on the first $90 \mu \mathrm{m}$ below the friction surface, the grains have their planes $\{200\}$-FCC (noted $\{001\}$ in the IPF) mainly parallel to the sliding surface. A slight crystallographic 


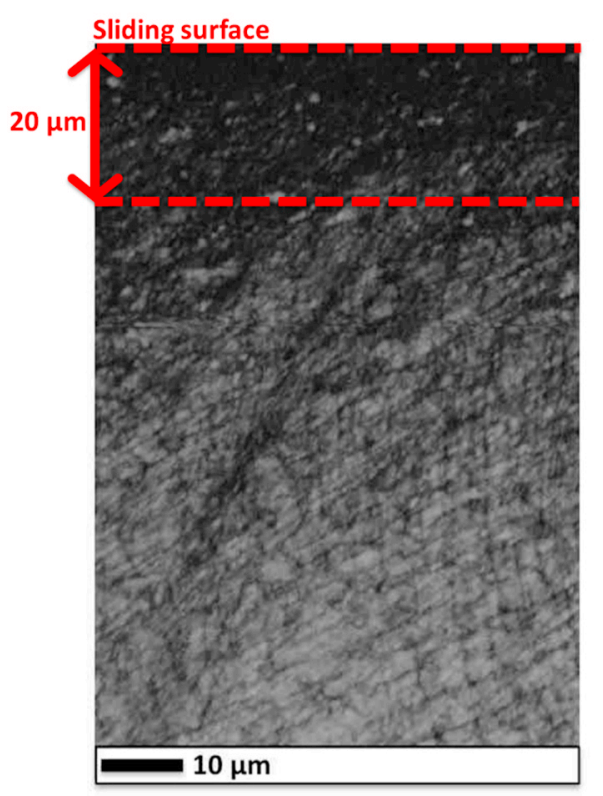

(a)

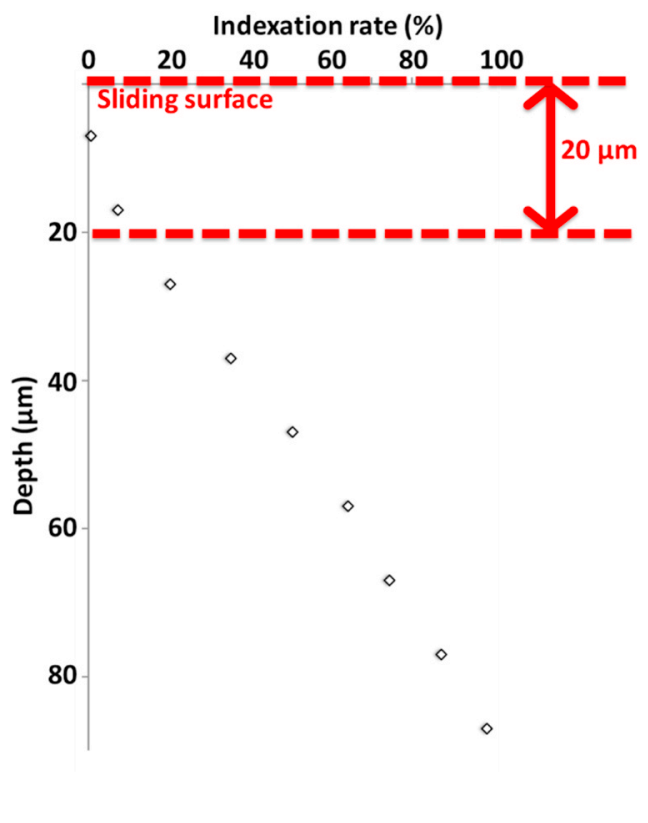

(b)

Fig. 18. Comparison between (a) the EBSD band contrast map and (b) the indexation rate versus the depth under the sliding surface.

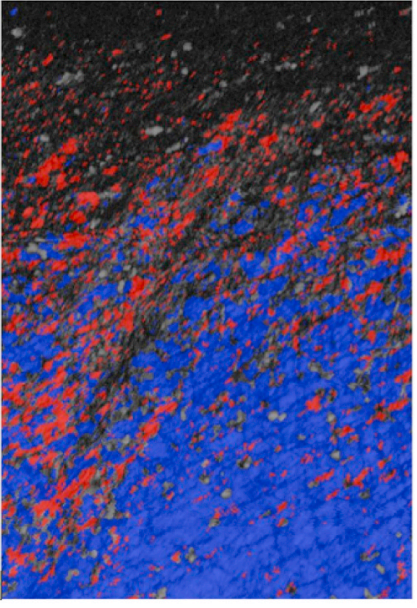

$10 \mu \mathrm{m}$

Fig. 19. EBSD phase map showing the FCC-Co phase in blue and the HCP-Co phase in red.

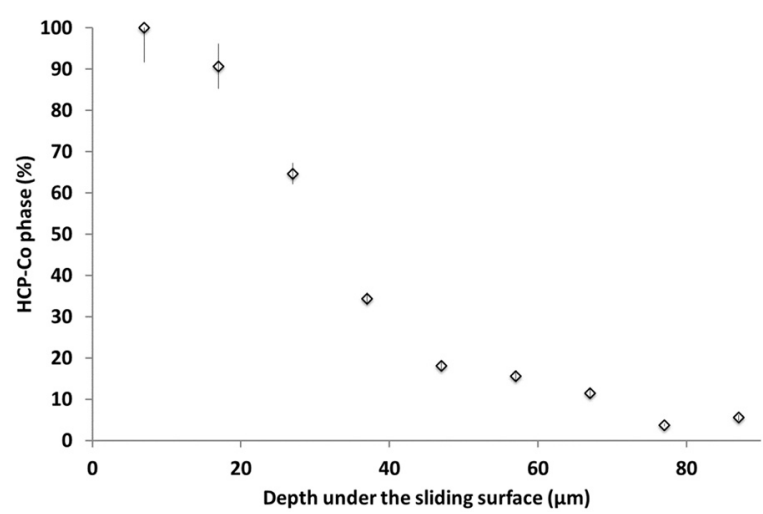

Fig. 20. Evolution of the HCP-Co content versus depth under the sliding surface.
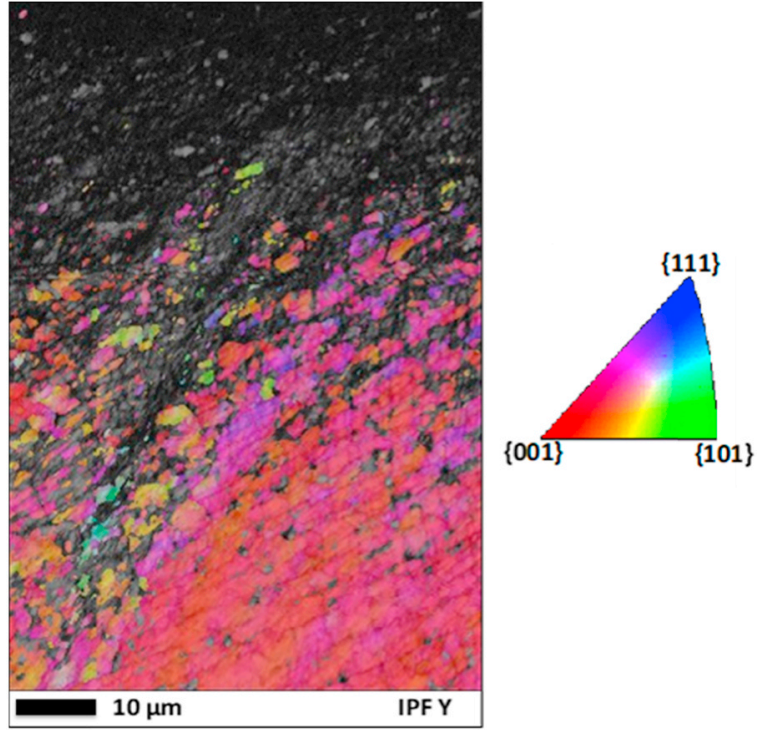

Fig. 21. IPF-Y map of the FCC-Co.

reorientation can be observed with a grain orientation intermediate between the $\{200\}$-FCC and the $\{111\}$ planes parallel to the sliding surface (Fig. 21).

Fig. 22 shows that the HCP grains have a preferred orientation along the three axes $\mathrm{X}, \mathrm{Y}$ and $\mathrm{Z}$. Therefore, the grains seem to be all oriented in a similar way with respect to the sliding load. As schematized on Fig. 23 the $\{0001\}$-HCP planes (i.e. the basal planes, noted $\{001\}$ in the IPF) are preferentially oriented parallel to the sliding surface (Fig. 22IPF Y) and the $\{01-10\}$ planes (i.e. the prismatic planes, noted $\{010\}$ in the IPF) are preferentially oriented perpendicular to radial direction (Fig. 22-IPF Z).

\section{Discussion}

As shown in this study, the FCC to HCP phase transformation (i.e. martensitic transformation) of the cobalt can be achieved or not on the 

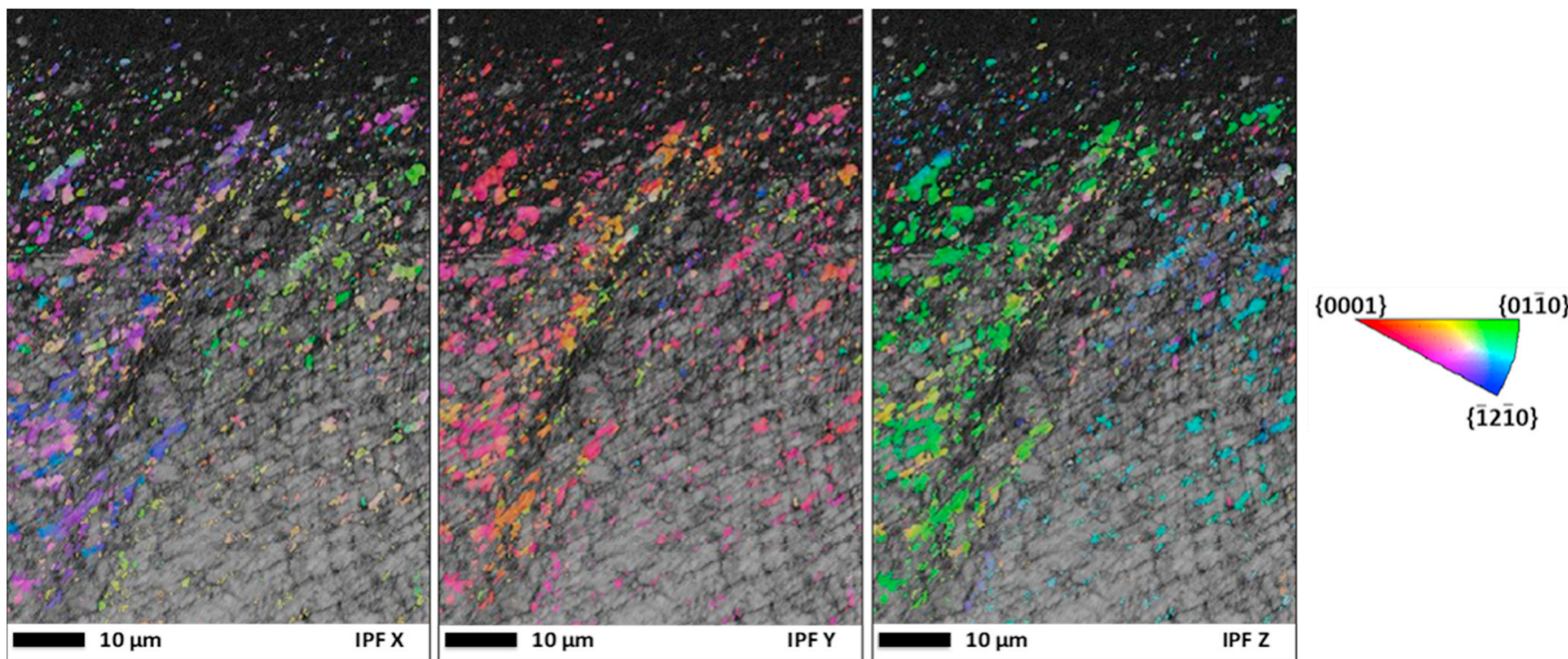

Fig. 22. IPF maps of the HCP-Co.

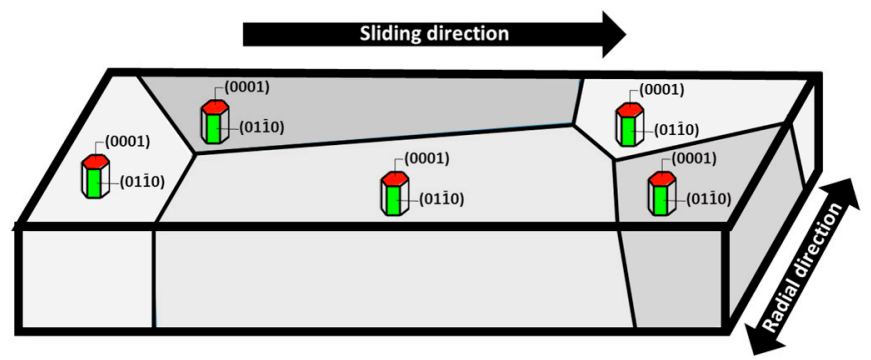

Fig. 23. Scheme of the preferred orientation of the HCP grains at the sliding surfaces of ST21-laser hardfacings.

Tribologically Transformed Surface (TTS). Indeed, as a result of the friction, the surface crystal structure of ST21-MIG hardfacings remained FCC while the surface crystal structure of ST21-laser hardfacings transformed from the initial FCC structure into the HCP structure. As the iron is known to have a strong influence on the SFE, stabilizing the FCC structure [2], these behavior differences can be correlated with the iron content in the hardfacings (dilution effect, number of layers).

\subsection{Correlation between friction coefficient and crystal structure in the TTS}

The friction coefficient evolutions versus sliding distance has shown two extremely different behaviors. A stable friction coefficient has been observed for the ST21-MIG while a decreasing and then stabilized friction coefficient has been observed for the ST21-laser hardfacings. Due to the crystal phase analyzes these differences in friction coefficient evolution can be related to the crystal structure of the TTS. Indeed, a stable friction coefficient could be associated with a FCC structure of the TTS while a friction coefficient decrease could be associated with a HCP structure of the TTS. This hypothesis has been reinforced by additional friction tests performed on a slightly different hardfacing (Stellite 6) deposited by laser process. Five tribological tests have been performed in the same conditions (Table 4 at RT) and they have been stopped at different friction coefficient values. The quantification of the crystal structures in the TTS has been performed by using classical $\theta-\theta$ measurement and the Rietveld method [17]. The results (Fig. 24) have demonstrated a very good relationship between the decrease of the friction coefficient and the HC phase content in TTS. So, the decrease of the friction coefficient can be correlated to the progressive martensitic transformation of the TTS. When the upper layers of the TTS are

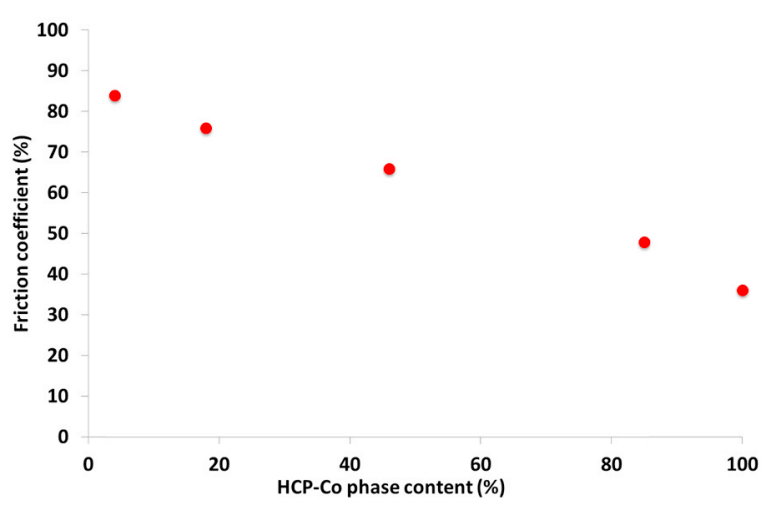

Fig. 24. Friction coefficient value versus HCP phase content in the TTS.

completely transformed into HCP, there is no more decrease of the friction coefficient, i.e. the friction coefficient is constant at low values for the remainder sliding distance. As the FCC-Co has twelve operating slip systems while the HCP-Co has three operating slip systems (the $\mathrm{c} / \mathrm{a}$ ratio is more than 1.62 for HCP-Co, so, it should exhibit basal slip), the difference of tribological behavior of the FCC and HCP crystal structure of the cobalt is believed to be related to the differences in slip behavior. The lower number of slip systems for the HCP structure of the cobalt than for the FCC structure of the cobalt may induce less "surface reactivity" under friction stresses.

The results have also shown that both hardfacings undergo a strong grain reorientation under friction loadings. Concerning the ST21-MIG hardfacings, remaining their FCC structure, the grains orientations evolution under tribological load corresponds to the alignment of the $\{111\}$-FCC planes (i.e. the main FCC slip planes) with the sliding surface. This grain reorientation can be directly linked to dislocations activity. Concerning the ST21-laser hardfacings, that undergo an FCC to HCP phase transformation, a texture is also observed with the alignment of the $\{0002\}$-HCP planes with the sliding surface. This grain orientation in the TTS, also well demonstrated by Person in ST21-laser hardfacings by TEM observations [4], could be explained by the orientation relation between FCC and HCP structure during the phase transformation. The latter is given by the Shoji-Nichiyama equation: $\{111\}_{\mathrm{FCC}} / /\{0002\}_{\mathrm{HCP}}:<1 \overline{1} 0>_{\mathrm{FCC}} / /<11 \overline{2} 0>_{\text {HCP. }}$. It would mean that before phase transformation, the FCC structure had already its grains reoriented with the $\{111\}$-FCC planes parallel to the sliding 
surface. So, before the crystallographic transformation, the grains had enough time to deform plastically by dislocations slip and thus to change orientation. The phase transformation is then achieved and the new phase has the same orientation of the FCC parent phase. Plastic deformation of the induced HCP phase seems to be too low to be responsible to the observed grain reorientation. It can be noted that no impact of the grain reorientation has been observed on the friction coefficient evolution. The latter is stable versus sliding distance for the ST21-MIG hardfacings despite a strong grain reorientation.

The temperature influence on the steady-state coefficient value has been studied in view of the crystal structure. The steady-state friction coefficient is lower at room temperature $(\approx 52.7 \%)$ than at high temperature $(\approx 73.7 \%)$ for an FCC structure. Thus, the FCC crystallographic structure "slides" better at room temperature then at high temperature. In contrary, the friction coefficient at room temperature $(\approx 28.6 \%)$ is slightly higher than the friction coefficient at high temperature $(\approx 39.9 \%)$. Thus, the HCP structure "slides" better at high temperature than at room temperature. However, the influence of the test temperature is less pronounced for the HCP structure than for the FCC structure.

\subsection{Correlation between wear and crystal structure in the TTS}

Concerning the plastic deformation, the higher ductility of the ST21-MIG hardfacings than the ST21-laser can also be explained thanks to crystallographic characterizations. As the FCC structure is well known to have more slip systems than the HCP structure, the fact that the ST21-MIG hardfacings stay under FCC structure could be responsible of a higher ductility and so an easiest and more important plastic deformation. By the way, the high texture of the TTS goes also in the direction of plasticity via essentially the sliding of perfect dislocations. Concerning the ST21-laser hardfacings, the plastic deformation would be less important because once the FCC to HCP transformation is achieved, the mechanisms of plasticity are less numerous (because HCP has much less sliding systems than FCC).

In parallel, the work-hardening for the ST21-MIG hardfacings seems to be mainly due to the multiplication and entanglement of dislocations in the FCC structure. The microstructure refinement could also be responsible of the increase of the hardness. For the ST21-laser, the workhardening can also be correlated to the multiplication of dislocations in the FCC phase and to the presence of HCP phase. The latter could limit the hardfacing ductility due to low slip systems. A good wear resistance is so observed for the ST21-laser that is less deformed under friction loading.

\section{Conclusions}

The tribological behavior of cobalt-based hardfacings has been investigated under sliding wear on a monolayer MIG hardfacing and a multilayer laser hardfacing, differing mainly in their iron content. Based on the results obtained in this work, the following conclusions can be drawn:

- Particularly depending on the iron content, and so on the stackingfault energy, the plasticity mechanisms involved can be perfect dislocation gliding and/or FCC to HCP phase transformation (i.e. martensitic transformation).

- The work-hardening and the grain reorientation of the Tribologically Transformed Surfaces (TTS) can be correlated to plasticity mechanisms by perfect dislocation gliding.

- A relationship has been demonstrated between the friction coefficient evolution and the FCC to HCP phase transformation (i.e. the HCP content in the TTS) in cobalt-based hardfacings.

- The HCP-Co crystal structure exhibits a lower friction coefficient, a lower ductility and a lower wear volume than the FCC-Co structure.

\section{Acknowledgements}

This work is part of ROOF2 project. It is a FUI12 project labialised by the competitiveness clusters ViaMeca, Aerospace Valley and the European ceramics centre. The ROOF2 project is funded by the Auvergne FEDER, the Auvergne Region, the Allier General Council, the FUI, the Saint-Etienne Metropolis, the Indre General Council, the Limousin Region and the Limousin FEDER.

\section{References}

[1] G.B. Olson, M. Cohen, A general mechanism of martensitic nucleation: Part I. General concepts and the FCC $\rightarrow$ HCP transformation, Metall. Trans. A 7A (1976) 1897-1904, https://doi.org/10.1007/BF02659822.

[2] C.T. Sims, N.S. Stoloff, W.C. Hagel, Superalloys II, Wiley, New York, 1987.

[3] A.J. Saldívar Garciá, A.M. Medrano, A.S. Rodríguez, Formation of hcp martensite during the isothermal aging of an fcc Co-27Cr-5Mo-0.05C orthopedic implant alloy, Metall. Mater. Trans. A 30 (5) (1999) 1177-1184, https://doi.org/10.1007/s11661999-0267-6.

[4] D.H.E. Persson, On the Mechanisms Behind the Tribological Performance of Stellites (Ph.D. Dissertation), (2005).

[5] H. Kashani, A. Amadeh, A. Ohadizadeh, Effect of temperature on the strain induced on the strain induced $\gamma \rightarrow \varepsilon$ phase transformation in Stellite 21 during wear test, Mater. Sci. Eng. A 435 (2006) 474-477.

[6] S. Atamert, H.K.D.H. Bhadeshia, Comparison of the microstructures and abrasive wear properties of stellite hardfacing alloys deposited by arc welding and laser cladding, Metall. Trans. A 20A (1989) 1037-1054, https://doi.org/10.1007/ BF02650140.

[7] H. Kashani, M. Sadeghi Laridjani, A. Amadeh, M. Khodagholi, S. Ahmadzadeh, The influence of volumetric dilution on the strain induced $\gamma \rightarrow \varepsilon$ martensitic transformation in GTAW processed Co-Cr-Mo alloy, Mater. Sci. Eng. A 478 (1-2) (2008) 38-42, https://doi.org/10.1016/j.msea.2007.05.061.

[8] K. Anderson, Stick vs. MIG vs. TIG: Which Process is Right For You?, Welding Supplies from IOC, 2015. Retrieved July 2018 from 〈https://www. weldingsuppliesfromioc.com/blog/stick-vs-mig-vs-tig-which-process-is-right-foryou/>.

[9] F. Geyer, Laser Metal Deposition \& Laser Metal Fusion: Comparison of Processes \& Their Uses, LasersToday ${ }^{T M}$, 2016. Retrieved July 2018 from 〈https://www. laserstoday.com/2016/05/laser-metal-deposition-laser-metal-fusion-comparisonof-processes-their-uses $>$.

[10] G. Lesoult, Solidification - Cristallisation et microstructures, Techniques de l'ingénieur, Paris, 1986.

[11] J.R. Davis, Nickel, Cobalt, and Their Alloys, AMS specialty handbook ${ }^{\circ}$, USA, 2000.

[12] K. Ishida, T. Nishizawa, The Co-Cr (cobalt-chromium) system, Bull. Alloy Phase Diagr. 11 (4) (1990) 357-370.

[13] D.H.E. Persson, Antigalling and low friction properties of a laser processed Co-based material, J. Laser Appl. 15 (2) (2003) 115-119, https://doi.org/10.2351/1. 1514218.

[14] L. Iordache, Analyse tribo-métallurgique des rechargements base cobalt par fusion soudage d'outillages à chaud (Ph.D.), (2006).

[15] M.L. Capp, J.M. Rigsbee, Laser processing of plasma-sprayed coatings, Mater. Sci. Eng. 62 (1984) 49-56, https://doi.org/10.1016/0025-5416(84)90266-0.

[16] B. Chassignole, Influence de la structure métallurgique des soudures en acier inoxydable austénitique sur le contrôle non destructive par ultrasons (Ph.D.), (2000).

[17] H.M. Rietveld, A profile refinement method for nuclear and magnetic structures, J. Appl. Crystallogr. 2 (1969) 65-71. 